\title{
Apparent-Strain Correction for Combined Thermal and Mechanical Testing ${ }^{1}$
}

\author{
Theodore F. Johnson ${ }^{*}$ and Teresa L. O’Neil. ${ }^{\dagger}$ \\ NASA Langley Research Center, Hampton, VA 23681-2199, USA
}

\begin{abstract}
Combined thermal and mechanical testing requires that the total strain be corrected for the coefficient of thermal expansion mismatch between the strain gage and the specimen or apparent strain when the temperature varies while a mechanical load is being applied. Collecting data for an apparent strain test becomes problematic as the specimen size increases. If the test specimen cannot be placed in a variable temperature test chamber to generate apparent strain data with no mechanical loads, coupons can be used to generate the required data. The coupons, however, must have the same strain gage type, coefficient of thermal expansion, and constraints as the specimen to be useful. Obtaining apparent-strain data at temperatures lower than $-320^{\circ} \mathrm{F}$ is challenging due to the difficulty to maintain steady-state and uniform temperatures on a given specimen. Equations to correct for apparent strain in a real-time fashion and data from apparent-strain tests for composite and metallic specimens over a temperature range from $-450^{\circ} \mathrm{F}$ to $+250^{\circ} \mathrm{F}$ are presented in this paper. Three approaches to extrapolate apparent-strain data from $-320^{\circ} \mathrm{F}$ to $-430^{\circ} \mathrm{F}$ are presented and compared to the measured apparent-strain data. The first two approaches use a subset of the apparent-strain curves between $-320^{\circ} \mathrm{F}$ and $100^{\circ} \mathrm{F}$ to extrapolate to $-430^{\circ} \mathrm{F}$, while the third approach extrapolates the apparent-strain curve over the temperature range of $-320^{\circ} \mathrm{F}$ to $+250^{\circ} \mathrm{F}$ to $-430^{\circ} \mathrm{F}$. The first two approaches are superior to the third approach but the use of either of the first two approaches is contingent upon the degree of non-linearity of the apparent-strain curve.
\end{abstract}

\section{Nomenclature}

\begin{tabular}{|c|c|}
\hline Al-2195 & $=$ aluminum-lithium 2195 \\
\hline CTE & $=$ coefficient of thermal expansion \\
\hline C-F LHe & $=$ liquid helium curve-fit \\
\hline $\mathrm{C}-\mathrm{F} \mathrm{LN} \mathrm{LN}_{2}$ & $=$ liquid nitrogen curve-fit \\
\hline$F(T)$ & $=$ gage factor at the test temperature \\
\hline$F^{*}$ & $=$ gage factor \\
\hline Gr-Ep & $=$ graphite-epoxy IM7/977-2 \\
\hline $\mathrm{LaRC}$ & $=$ NASA Langley Research Center \\
\hline $\mathrm{LN}_{2}$ & $=$ liquid nitrogen \\
\hline $\mathrm{LHe}$ & $=$ liquid helium \\
\hline $\mathrm{LH}_{2}$ & $=$ liquid hydrogen \\
\hline K-alloy & $=$ Karma alloy \\
\hline NASA & $=$ National Aeronautics and Space Administration \\
\hline NTF & $=$ National Transonic Facility \\
\hline PMC & $=$ polymeric matrix composite \\
\hline RT & $=$ room temperature \\
\hline STC & $=$ self-temperature-compensation \\
\hline STC\# & $=$ self-temperature-compensation number \\
\hline
\end{tabular}

${ }^{1}$ Copyright 2007 by the American Institute of Aeronautics and Astronautics, Inc. No copyright is asserted in the United States under Title 17, U.S. Code. The U.S. Government has a royalty-free license to exercise all rights under the copyright claimed herein for Governmental purposes. All other rights are reserved by the copyright owner.

${ }^{*}$ Research Engineer, Structures and Thermal Systems Branch /Mail Stop 431, AIAA Member.

${ }^{\dagger}$ Research Technician, Applied Technology and Test Branch, Technical Research Section D /Mail Stop 188D. 


$$
\begin{array}{ll}
T & =\text { temperature } \\
\text { Titanium } & =\text { titanium Ti-6Al-4V } \\
\varepsilon & =\text { strain } \\
\varepsilon_{C} & =\text { corrected strain } \\
\varepsilon_{T e s t} & =\text { indicated strain (measured strain) } \\
\varepsilon_{T / 0}(T) & =\text { thermal output of the strain gage }
\end{array}
$$

\section{Introduction}

$\mathrm{T}$ HE development of cryogenic propellant tanks for launch vehicles, shown in Figure 1, requires testing of coupon, panel, and subcomponent specimens to verify the performance of the structures and materials ${ }^{1}$. These specimens are typically tested under combined thermal and mechanical loading, where the temperature extreme ranges from $-423^{\circ} \mathrm{F}$ to the maximum-use temperature of the materials ${ }^{2}$. Strain is usually measured in these specimens using metallic foil strain gages bonded to the specimens. Since the metallic or polymeric matrix

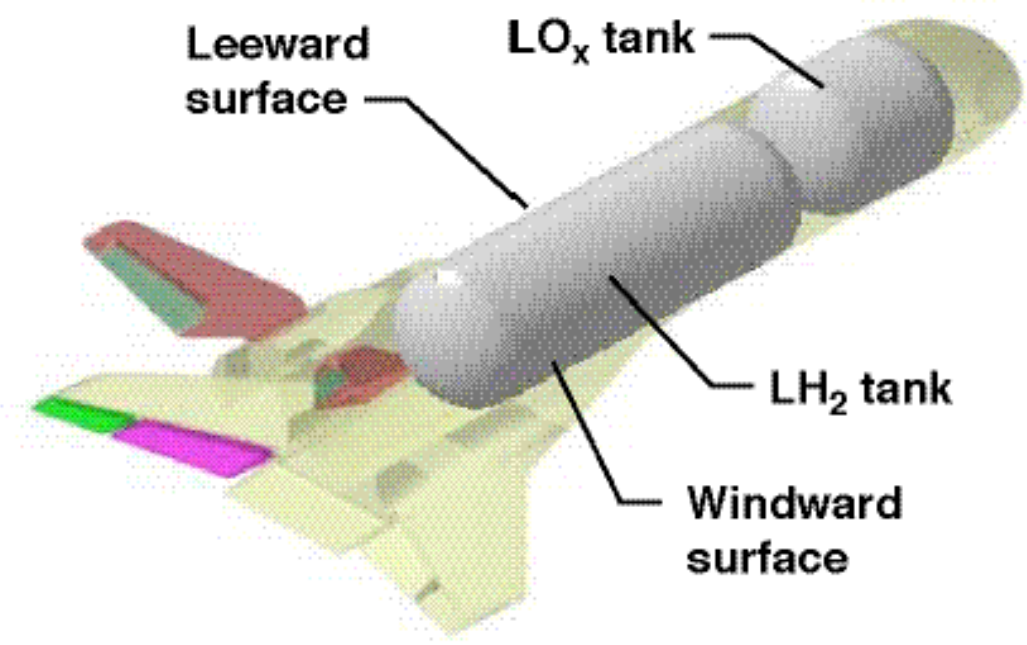

Figure 1. A generic launch vehicle with an aft- or forward-located $\mathrm{LH}_{2} \operatorname{tank}$. composite (PMC) substrate may have a coefficient of thermal expansion (CTE) different than the strain gage, a difference between the measured strain and the true strain when the specimen is subjected to temperature change may occur. This difference in strain is known as the thermal output or the apparent strain of the strain gage.

Temperature change is usually not a factor if the specimen is tested near isothermal conditions (i.e., changes in temperature limited to $\left.+/-10^{\circ} \mathrm{F}\right)$. In isothermal tests, once the specimen has achieved a steady-state temperature with no mechanical loads, the measured strain of the strain gage is set to zero and then the mechanical loads are applied. If the specimen is subjected to temperature changes while being mechanically loaded, the difference in the thermal output of the strain gage and true strain can be accounted for by determining the thermal output of the strain gage over the range of test temperatures using apparent-strain tests. Once the temperature-dependent thermal output of the strain gage is determined, a curve is fit through the data. The curve fit is used to correct the measured strain to obtain the corrected or true strain in a real-time fashion. This method is called mathematical compensation ${ }^{3}$.

Occasionally, the test article either cannot be used to measure the thermal output of a strain gage in the test facility without a mechanical load being introduced into the specimen during the apparent-strain test or the lowest desired temperature cannot be achieved in the apparent-strain test with the test article. In these cases, apparentstrain coupons in an unloaded state are utilized to generate the thermal output of the strain gage data at all possible test temperatures. Also, if the lowest temperature could not be achieved on the actual test article in the apparentstrain test, the apparent-strain coupons can be used to determine characteristic thermal output of the strain gage curves. One can assume that the thermal output of a strain gage is characteristic if all of the strain gages in a characteristic family are located on a substrate that has the same CTE in both directions and the substrate is constrained in the same manner ${ }^{3}$. The characteristic curves can be used to extrapolate the thermal output of the strain gage curves created for a test article from an apparent-strain test so that if the test article is exposed to temperatures below the lowest temperature achieved during the apparent-strain test, the strain can still be corrected. 
A second compensation method for the thermal output of the strain gage is to use "dummy" or witness strain gages $^{3}$. The witness strain gage is placed close to the test strain gage on the specimen and not connected or bonded to the specimen so that the witness strain gage experiences the same temperature as the test strain gage but no mechanical strain. The thermal output of the witness strain gage is subtracted from the test strain to obtain true strain values in a real-time fashion. The drawbacks to this method are: one is not assured to obtain the same temperature for the test strain gage and the witness strain gage at all times; if the witness gage is or becomes inoperable, the true strain of the test gage cannot be determined in real-time; and one doubles the number of stain gages and thermocouples used in the test.

Extensive test programs have been conducted to investigate apparent strain since the onset of using metallic foil strain gage in combined thermal and mechanical. Telinde ${ }^{4}$ conducted tests to study the effects of cryogenic and high temperatures by testing strain gages mounted on a plate in a temperature range from $-452^{\circ} \mathrm{F}$ to $+500^{\circ} \mathrm{F}$. Ferris ${ }^{5,6}$, at NASA Langley Research Center (LaRC), conducted numerous tests for apparent strain to calibrate 6 in. to 7 in. balances used in the National Transonic Facility (NTF) Wind Tunnel at LaRC. Mikesell, et. al. ${ }^{3}$ used coupons to generate apparent-strain data for the Centaur launch vehicle stainless-steel liquid hydrogen $\left(\mathrm{LH}_{2}\right)$ propellant tank tests. During the X-33 Program ${ }^{1}$, tests were developed at LaRC for the cryogenic propellant tanks ${ }^{2,7,8}$ and the study of apparent strain on coupons was conducted by Kowalkowski et. al. ${ }^{9}$ in conjunction with these tests. In the tests conducted by Johnson et al. ${ }^{2,7}$, apparent strain tests were conducted on the actual specimen except for a $5 \mathrm{ft}$. by $6 \mathrm{ft}$. curved-panel specimen. Apparent strain tests could only be performed in the range from $-340^{\circ} \mathrm{F}$ to $+250^{\circ} \mathrm{F}$ for the curved-panel specimen. The specimen, however, would be exposed to temperatures below $-400^{\circ} \mathrm{F}$ under combined mechanical and pressure loads. Once the testing was completed, coupons were to be removed and apparent tests at the lower temperatures were to be conducted to correct for true strain for the final data package. In the interim, the apparent-strain curves were extrapolated to lower temperatures using the curve-fit of the apparent-strain data from $340^{\circ} \mathrm{F}$ to $+250^{\circ} \mathrm{F}$ and the thermal-output of the strain gage equation from the strain gage manufacturer for the realtime tests to provide an estimate for the true strain.

A more robust approach is required for future testing of panels where the specimen cannot have an apparentstrain test over the complete range of temperatures and where there are no coupons available for separate apparentstrain tests. One approach is to accept that the apparent-strain curves are characteristic and an extrapolation can be used to cover the temperature range not tested. The results from apparent-strain coupons tested to liquid nitrogen $\left(\mathrm{LN}_{2}\right)$ temperatures $\left(-320^{\circ} \mathrm{F}\right)$ and liquid helium $(\mathrm{LHe})$ temperatures $\left(-452^{\circ} \mathrm{F}\right)$ and up to $+250^{\circ} \mathrm{F}$, will be presented in this paper. Methods to correct for thermal output of the strain gage or apparent strain are also presented. The thermal output of the strain gages are compared to show that the curves for the thermal output of the strain gages can be extrapolated for a test article that does not have test data at the lowest required test temperatures.

\section{Apparent-Strain Correction}

Descriptions of the theory involved in correcting for the true strain using the thermal output of the strain gage are contained in Refs. 9, 11. The equations used to correct for the thermal output of the strain gage are presented in this section. Henceforth, the thermal output of the strain gage will be called thermal output.

There are two quantities for a strain gage that can vary as the temperature changes during a test, the gage factor, $F^{*}$, and the thermal output, $\varepsilon_{T / 0}(T)$, where $T$ is the temperature. The room-temperature gage factor, $F^{*}$, is provided by the strain gage manufacturer and usually used in the apparent-strain test and throughout the combined thermal and mechanical test. The strain gage manufacturer also provides a thermal-output equation that can be used over a temperature range of $-320^{\circ} \mathrm{F}$ to the maximum temperature of the strain gage. The thermal-output equation from the strain gage manufacturer is obtained from apparent-strain tests where a strain gage is bonded on an unconstrained plate that had a CTE very close to the CTE of the strain gage. The test strain gage may be placed on the substrate that may be constrained, has additional structural features and/or a slightly different CTE in various directions. The thermal output, $\varepsilon_{T / 0}(T)$, for a strain gage on a specimen, however, is determined in apparent-strain tests, especially if the specimen will be exposed to temperatures less than $-320^{\circ} \mathrm{F}$. A curve-fit of the data is calculated to determine thermal output over a range of temperatures using the data from the apparent-strain test.

The correction for thermal output is given as

$$
\varepsilon_{C}=\varepsilon_{T e s t}-\varepsilon_{T / 0}(T)
$$


where $\varepsilon_{C}$ is the strain corrected for thermal output only and, $\varepsilon_{\text {Test }}$ is the indicated strain (measured strain) that is uncorrected for either thermal output or gage factor variation with temperature during the actual test. The correction of the gage factor variation with respect to temperature must be calculated and included in the correction thermal output. The apparent-strain test was performed with a gage factor set at $F^{*}$ but the gage factor changes as the temperature changes, affecting the strain output from the strain gage, thus,

$$
\varepsilon_{1}=\varepsilon_{C} \frac{F^{*}}{F(T)}
$$

where, $\varepsilon_{1}$ is the strain corrected both for thermal output and the gage factor variation with respect to temperature and $F(T)$ is the gage factor at the test temperature. The function or slope from room temperature (RT) for the temperature-dependent gage factor, $F(T)$, is usually provided by the strain gage manufacturer and varies linearly with respect to temperature. Combine eqn. 1 and eqn. 2 to obtain

$$
\varepsilon_{1}=\left[\varepsilon_{T e s t}-\varepsilon_{T / 0}(T)\right] \frac{F^{*}}{F(T)}
$$

for an equation that can be used to calculate the corrected strain for both thermal output and the gage factor variation of the strain gage with test temperature.

\section{Apparent-Strain Tests}

Four apparent-strain tests were conducted with coupons to determine the thermal output of strain gages bonded on to three different substrates: graphite-epoxy IM7-977-2 (Gr-Ep), Aluminum-Lithium 2195 (Al-2195), and Titanium Ti-6Al-4V (Titanium). The Gr-Ep substrates had a laminate stacking sequence of $\left[45 / 90_{3} /-45 / 0_{3} /-\right.$ $\left.45 / 90_{3} / 45\right]^{15}$. The materials are listed in Table 1 with the CTEs, thickness, density, self-temperature-compensation (STC) number, operational temperatures, and test temperatures. The maximum temperature will be limited to $+250^{\circ} \mathrm{F}$ even though titanium can be used up to $+900^{\circ} \mathrm{F}$.

Table 1. Substrates, CTEs, thickness, density, STC number, and minimum- and maximum-use and test temperatures used in the apparent-strain tests.

\begin{tabular}{c|c|c|c|c|c|c|c|c|c|c}
\hline \hline \multirow{2}{*}{ Material } & $\begin{array}{c}0^{\circ} \text {-Dir. } \\
\mathrm{CTE} \\
\mathrm{x} 10^{-6} /{ }^{\circ} \mathrm{F}\end{array}$ & $\begin{array}{c}90^{\circ} \text {-Dir. } \\
\mathrm{CTE} \\
\mathrm{x} 10^{-6} /{ }^{\circ} \mathrm{F}\end{array}$ & $\begin{array}{c} \pm 5^{\circ} \text {-Dir. } \\
\mathrm{CTE} \\
\mathrm{x} 10^{-6} /{ }^{\circ} \mathrm{F}\end{array}$ & $\begin{array}{c}\text { Thickness } \\
\text { in. }\end{array}$ & $\begin{array}{c}\text { Density } \\
\text { lbs/in. }{ }^{3}\end{array}$ & STC\# & $\begin{array}{c}\text { Min. } \\
{ }^{\circ} \mathrm{F}\end{array}$ & $\begin{array}{c}\text { Max. } \\
{ }^{\circ} \mathrm{F}\end{array}$ & $\begin{array}{c}\text { Min. } \\
{ }^{\circ} \mathrm{F}\end{array}$ & $\begin{array}{c}\text { Max. } \\
{ }^{\circ} \mathrm{F}\end{array}$ \\
\hline Gr-Ep & 1.454 & 0.400 & 0.927 & 0.083 & 0.057 & 03 & -423 & +250 & -452 & +250 \\
\hline Al-2195 & 12.6 & 12.6 & 12.6 & 0.125 & 0.0975 & 13 & -423 & +250 & -452 & +250 \\
\hline Titanium & 5.5 & 5.5 & 5.5 & 0.0625 & 0.160 & 06 & -423 & +900 & -452 & +250 \\
\hline \hline
\end{tabular}

Note:

Gr-Ep data is from Ref. 12

AL-2195 data is from Ref. 13

Titanium data is from Ref. 14

Uniaxial: WK-STC\#-125AD-350

Rosette: WK-STC\#-125RA-350

\section{A. Specimen Instrumentation}

Two types of 0.125 in., 350-ohms, Micromeasurements Groups ${ }^{\ddagger}$ strain gages were used, a single-arm uniaxial, (WK-STC\#-125AD-350), and a three-arm rosette (WK-STC\#-125RA-350) where STC\# is the STC number. These strain gages were bonded on to the substrate, shown in Figure 2, using the process outlined in Ref. 10. The procedures outlined by Moore ${ }^{10}$ assure that the strain gages will survive the extreme temperature conditions of combined thermal and mechanical load. The WK-type strain gages or K-alloy (modified Karma) are the suggested gages for measuring strain in the temperature extremes that a launch vehicle cryogenic tank may experience ${ }^{11}$. The STC number in Table 1 was selected based on the CTE of the substrate ${ }^{4,11}$. Substrates with a low CTE would use a low-numbered STC number to match the strain gage with the substrate. If a mismatch in STC number and CTE occurs, as the STC number increases, the shape of the apparent-strain curve rotates in clockwise fashion about RT

\footnotetext{
* This is not an endorsement by the National Aeronautics and Space Administration (NASA).
} 
on the $\mathrm{x}$-axis and the curve is less linear in nature ${ }^{3}$. A temperature-dependent plot comparing STC-number mismatch of WK strain gages on 301 stainless steel from Ref. 3 is shown in Figure 2. Type-E thermocouples were used to measure the temperature near the strain gages, see Figure $3 \mathrm{c}$, since these thermocouples provide an accurate measurement of temperature over the wide range of temperatures to which the coupons will be exposed ${ }^{2}$. All of the instrumentation had $20 \mathrm{ft}$. leads made of Teflon ${ }^{\mathrm{TM}}$ coated wire. Teflon ${ }^{\mathrm{TM}}$ coated wires were used to prevent cracking during thermal excursions.

Schematics of the test specimen configuration of sensors and the Gr-Ep specimen are shown in Figures $3 \mathrm{a}$ and $3 \mathrm{~b}$, respectively. The Al-2195 and Titanium specimens are also shown in Figures $3 \mathrm{c}$ and $3 \mathrm{~d}$, respectively. Uniaxial strain gage, SG 1 , is orientated in the $0^{\circ}$-direction and uniaxial strain gage, SG 2, is orientated in the $90^{\circ}$-direction. The rosette gage is orientated such that SG 3, arm-1, SG 4, arm-2, SG 5, arm-3 are in the, $-45^{\circ}-, 0^{\circ}-$, and $+45^{\circ}$ directions, respectively. A type-E thermocouple is placed next to each strain gage.

\section{B. Apparent-Strain Testing}

Four separate apparent-strain tests were performed. All four of the tests were repeated three times. The first test was conducted to obtain the thermal output at $\mathrm{LN}_{2}$ temperatures $\left(-320^{\circ} \mathrm{F}\right)$ using a vacuum-jacketed dunk tank with a

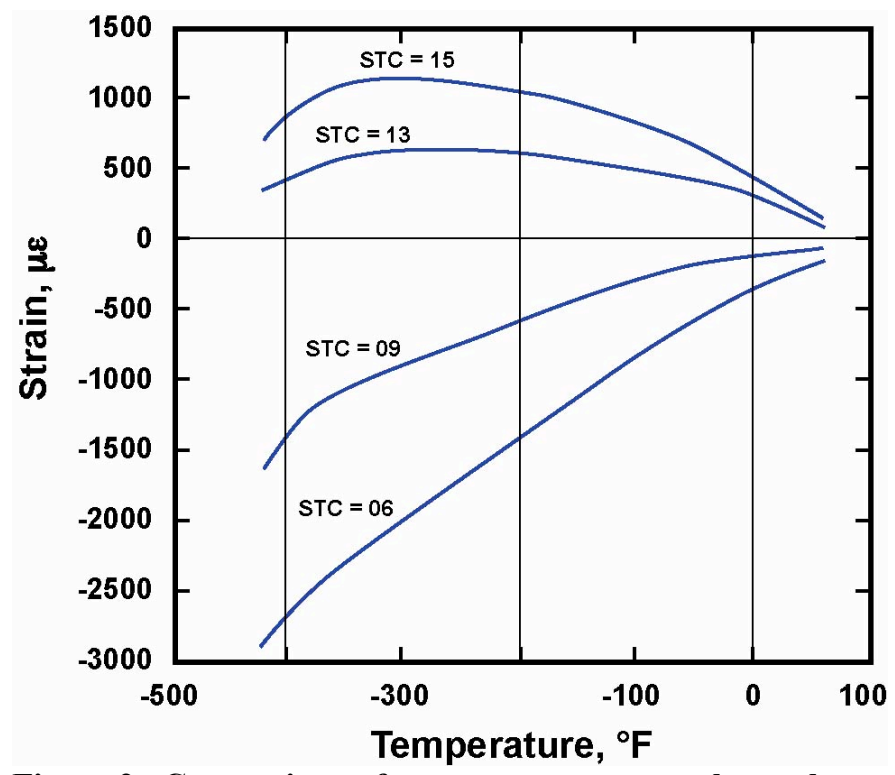

Figure 2. Comparison of temperature versus thermal output of strain gages with different STC numbers bonded on 301 stainless steel.
$\mathrm{LN}_{2}$ reservoir (unfilled), shown in Figure 4. The second test was performed to obtain data from RT $\left(70^{\circ} \mathrm{F}\right)$ and $+50^{\circ} \mathrm{F}$ to $-250^{\circ} \mathrm{F}$ in $50^{\circ} \mathrm{F}$ decrements using a temperature-controlled oven, shown in Figure 5, with $\mathrm{LN}_{2}$ as the coolant. The third test was performed to determine the thermal output from RT and $+100^{\circ} \mathrm{F}$ to $+250^{\circ} \mathrm{F}$ in $50^{\circ} \mathrm{F}$ increments using the same oven shown in Figure 5. In the fourth test, the vacuum-jacketed dunk tank, with the $\mathrm{LN}_{2}$ reservoir filled, was used to obtain data at $\mathrm{LHe}^{\S}$ temperatures $\left(-452^{\circ} \mathrm{F}\right)$ to $350^{\circ} \mathrm{F}$. For the LHe dunk tests, the specimens were immersed in the LHe then slowly warmed to $-300^{\circ} \mathrm{F}$ inside of an insulated chamber. This sequence of testing was followed to guarantee that the specimen would survive all of the testing. If the strain gage failed in the tests using $\mathrm{LN}_{2}$, the gage could be repaired or discarded. The tests at $\mathrm{LHe}$ were performed last since this was when the straingages had the highest probability of failing due to exposure to extreme temperatures.

The specimens were cooled or heated to a desired temperature and held at that temperature for twenty minutes to assure achieving a steady-state temperature condition in all of the tests. After twenty minutes, data were recorded at 0.5 second intervals. Data over a ten second period (twenty data points) were averaged and tabulated. Data were collected ten times per second for the LHe dunk tests since the temperature changed rapidly as soon as the specimens were removed from the LHe. Data over a two second period (twenty data points) were also averaged and tabulated for the LHe dunk tests.

\section{Apparent-Strain Test Results}

The results from the tests are presented in the form of plots and tables of the thermal output from the strain gage versus temperature for the uniaxial and rosette gages. The results for the $\mathrm{LN}_{2}, \mathrm{RT}$ to $-250^{\circ} \mathrm{F}$, RT to $+250^{\circ} \mathrm{F}$, and LHe apparent-strain tests are combined into one data set. The averaged data and the standard deviation for the three specimens Gr-Ep, Al-2195, and Titanium are listed in Tables 2, 3, and 4,

$\S$ The lowest temperature a launch vehicle propellant tank can be exposed to during operational use is liquid hydrogen $\left(\mathrm{LH}_{2}\right)$ temperatures $\left(-423^{\circ} \mathrm{F}\right) . \quad \mathrm{LH}_{2}$ could not be used because of the hazardous nature of $\mathrm{LH}_{2} ; \mathrm{LHe}$ was used instead. 
respectively. In Figures 6, 7, and 8 the data in Tables 2, 3, and 4 are plotted, respectively, with temperature versus averaged strain without the standard deviations.

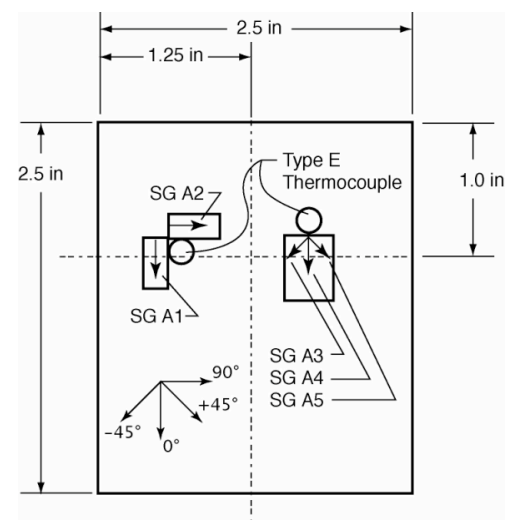

a) Specimen schematic

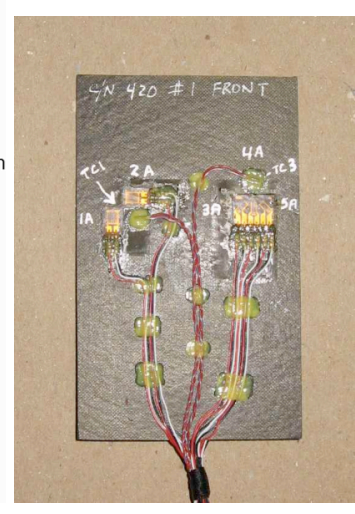

b) Gr-Ep specimen

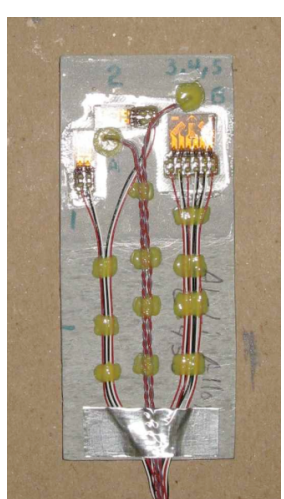

c) Al-2195 specimen

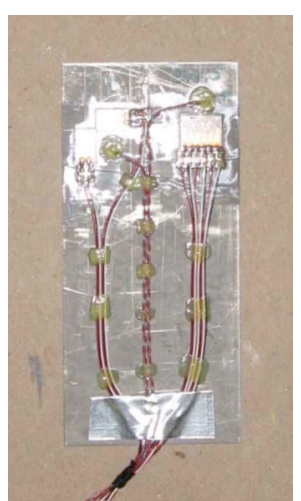

d) Titanium specimen

Figure 3. a) Schematic of the strain-gage locations and sensor types and pictures of the b) Gr-Ep, c) Al-2195, and d) Titanium apparent-strain specimens.

\section{Gr-Ep Data}

The apparent strain test results for the Gr-Ep specimen are listed in Table 2, with the averaged thermal output and the standard deviation for three runs. The averaged thermal output varies with temperature and the standard deviation of the thermal output is very low with respect to the averaged thermal output.

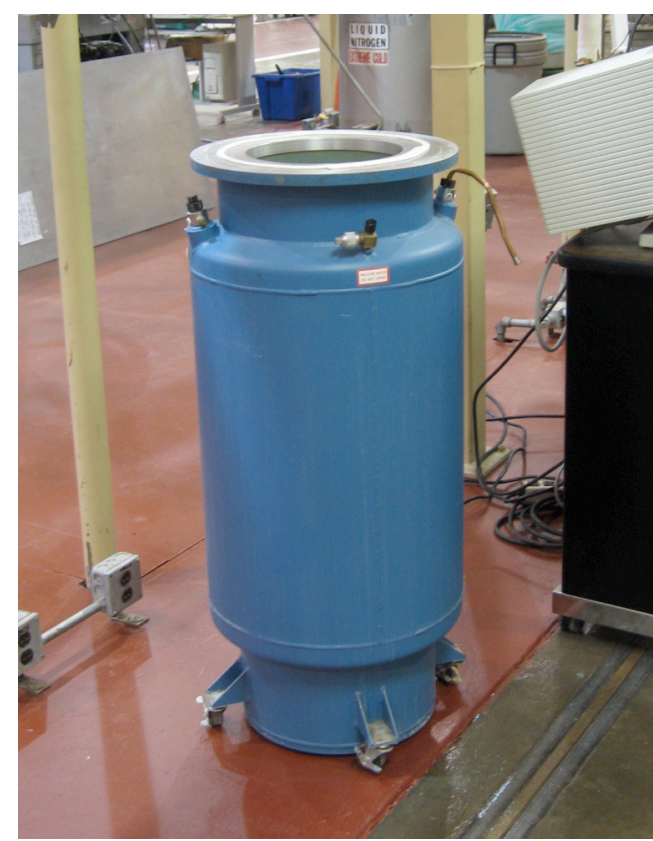

Figure 4. The vacuum-jacketed dunk tank with a $L N_{2}$ reservoir used in the $L N_{2}$ and LHe apparentstrain testing.

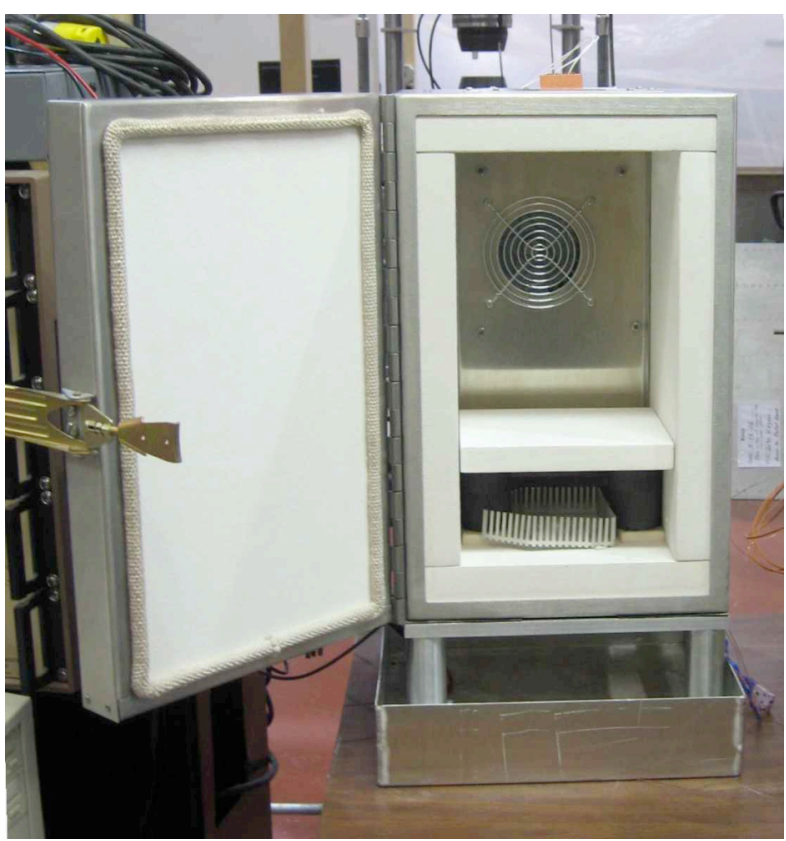

Figure 5. The temperature-controlled oven used to perform cryogenic temperature $\left(-250^{\circ} \mathrm{F}\right.$ to $\left.\mathrm{RT}\right)$ and high temperature to $\left(\mathrm{RT}\right.$ to $\left.+250^{\circ} \mathrm{F}\right)$ apparent-strain tests at $50^{\circ} \mathrm{F}$ increments.

The data in Table 2 is plotted in Figure 6 with the thermal-output curves for the uniaxial and rosette strain gages from the strain gage manufacturer. Three dominant thermal-output curves emerge for the tested strain gages. The 
thermal-output curves for strain gages SG 1 and SG 4, in the $0^{\circ}$-direction are almost the same and comprise the lower dominate. The thermal-output curves for strain gages SG 3 and SG 5, in the $-45^{\circ}$ - and $+45^{\circ}$-directions, respectively, are also almost the same. The thermal-output curve for strain gage, SG 2, in the $90^{\circ}$-direction stands alone.

Table 2. Averaged temperature-dependent apparent strain and standard deviation for the Gr-Ep specimen with two uniaxial strain gages and a rosette strain gage.

\begin{tabular}{c|c|c|c|c|c|c|c|c|c|c}
\hline \hline $\begin{array}{c}\text { Temp. } \\
{ }^{\circ} \mathrm{F}\end{array}$ & $\begin{array}{c}\text { SG 1 } \\
\mu \varepsilon\end{array}$ & $\begin{array}{c}\text { St. Dev. } \\
\mu \varepsilon\end{array}$ & $\begin{array}{c}\text { SG 2 } \\
\mu \varepsilon\end{array}$ & $\begin{array}{c}\text { St. Dev. } \\
\text { SG 2 } \\
\mu \varepsilon\end{array}$ & $\begin{array}{c}\text { SG 3 } \\
\mu \varepsilon\end{array}$ & $\begin{array}{c}\text { St. Dev. } \\
\text { SG 3 } \\
\mu \varepsilon\end{array}$ & $\begin{array}{c}\text { SG 4 } \\
\mu \varepsilon\end{array}$ & $\begin{array}{c}\text { St. Dev. } \\
\text { SG 4 } \\
\mu \varepsilon\end{array}$ & $\begin{array}{c}\text { SG 5 } \\
\mu \varepsilon\end{array}$ & $\begin{array}{c}\text { St. Dev. } \\
\mu \varepsilon\end{array}$ \\
\hline+250 & 1805 & 124 & -793 & 12 & 555 & 63 & 1802 & 122 & 510 & 60 \\
\hline+200 & 1324 & 52 & -543 & 6 & 419 & 32 & 1321 & 53 & 388 & 32 \\
\hline+150 & 813 & 12 & -302 & 8 & 270 & 10 & 808 & 14 & 252 & 11 \\
\hline+100 & 317 & 38 & -103 & 12 & 112 & 14 & 315 & 41 & 105 & 14 \\
\hline+70 & 3 & 0 & -1 & 1 & 1 & 0 & 2 & 1 & 1 & 1 \\
\hline+50 & -207 & 11 & 58 & 2 & -74 & 2 & -197 & 6 & -69 & 2 \\
\hline 0 & -730 & 7 & 169 & 1 & -276 & 4 & -699 & 11 & -262 & 5 \\
\hline-50 & -1297 & 22 & 227 & 2 & -517 & 8 & -1228 & 20 & -492 & 10 \\
\hline-100 & -1866 & 16 & 220 & 5 & -779 & 12 & -1743 & 24 & -745 & 14 \\
\hline-150 & -2457 & 7 & 143 & 5 & -1088 & 8 & -2285 & 17 & -1047 & 10 \\
\hline-200 & -3110 & 65 & -22 & 16 & -1458 & 41 & -2872 & 67 & -1411 & 41 \\
\hline-250 & -3694 & 18 & -230 & 10 & -1821 & 11 & -3404 & 19 & -1767 & 12 \\
\hline-320 & -4561 & 15 & -612 & 2 & -2442 & 9 & -4261 & 22 & -2353 & 11 \\
\hline-350 & -4781 & 22 & -832 & 30 & -2761 & 52 & -4643 & 24 & -2697 & 30 \\
\hline-360 & -4943 & 47 & -930 & 27 & -2900 & 94 & -4825 & 141 & -2852 & 115 \\
\hline-370 & -5084 & 85 & -1026 & 27 & -3002 & 38 & -4933 & 107 & -2934 & 78 \\
\hline-380 & -5262 & 109 & -1133 & 32 & -3114 & 45 & -5079 & 52 & -3057 & 40 \\
\hline-390 & -5411 & 111 & -1236 & 20 & -3185 & 91 & -5151 & 88 & -3118 & 69 \\
\hline-400 & -5525 & 85 & -1325 & 12 & -3219 & 98 & -5194 & 97 & -3150 & 76 \\
\hline-410 & -5620 & 72 & -1414 & 18 & -3266 & 93 & -5253 & 85 & -3189 & 58 \\
\hline-420 & -5692 & 56 & -1471 & 26 & -3273 & 84 & -5263 & 64 & -3189 & 44 \\
\hline-430 & -5739 & 52 & -1492 & 44 & -3285 & 56 & -5282 & 41 & -3199 & 25 \\
\hline-440 & -5737 & 56 & -1477 & 62 & -3311 & 26 & -5321 & 57 & -3224 & 55 \\
\hline-450 & -5609 & 4 & -1330 & 4 & -3168 & 3 & -5157 & 3 & -3054 & 6 \\
\hline \hline
\end{tabular}

Note:

SG 1 is a uniaxial strain gage in the $0^{\circ}$-direction.

SG 2 is a uniaxial strain gage in the $90^{\circ}$-direction.

SG 3 is arm-1 of a rosette strain gage in the $-45^{\circ}$-direction.

SG 4 is arm- 2 of a rosette strain gage in the $0^{\circ}$-direction.

SG 5 is arm-3 of a rosette strain gage in the $+45^{\circ}$-direction.

The Telinde effect ${ }^{4}$ is exhibited in all five thermal-output curves at temperatures below $-430^{\circ} \mathrm{F}$. The Telinde effect is when at temperatures below $-430^{\circ} \mathrm{F}$, the strain gage can become a superconductor, and the thermal output increases instead of decreasing as the temperature decreases.

CTE mismatch with the STC number for the strain gages was exhibited for SGs 1, and 4. The thermal-output curves for SGs 1 and 4 were below the thermal-output curves from the strain gage manufacturer since the CTE of the Gr-Ep specimen in Table 1 for the $0^{\circ}$-direction was the highest CTE. The thermal-output curve for SGs 1 and 4 became more linear and rotated in a counter-clockwise direction from the thermal-output curves from the strain gage manufacturer. SG 2 was oriented in the transverse or $90^{\circ}$-direction with a low CTE compared to the other material directions in Table 1 thus, the thermal-output curve rotated in the clockwise direction away from the thermal-output 
curve from the strain gage manufacturer and became more non-linear. SGs 3 and 5 in the $-45^{\circ}-$ and $+45^{\circ}$-directions, respectively, had a moderate CTE in Table 1 and the thermal-output curve fell between the curve for SGs 1 and 4 and SG 2 near the thermal-output curves from the strain gage manufacturer. The curve for SGs 3 and 5 also became more non-linear. Only three thermal-output curves SG $1 \& 4$ for SGs 1 and 4, SG 2, and SG 3\&5, for SGs 3 and 5 , will be used in subsequent discussions for the Gr-Ep specimen.

D. Al- 2195 data

The apparent-strain test results for the A1-2195 specimen are listed in Table 3, showing the averaged thermal

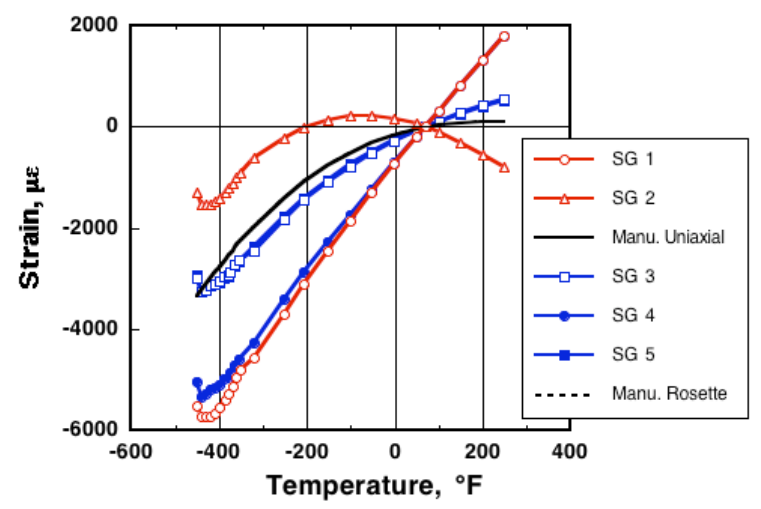

Figure 6. Apparent-strain results for the thermal output of the Gr-Ep specimen strain gages over the temperature range of $-450^{\circ} \mathrm{F}$ to $+250^{\circ} \mathrm{F}$. output and the standard deviation for three runs. The averaged thermal output varies with temperature and the standard deviation of the thermal output is very low with respect to the averaged thermal output.

One dominant curve is shown in the plot in Figure 7 based on Table 3 with the thermal-output curves for the uniaxial and rosette strain gages from the strain gage manufacturer. The curves for all of the strain gages, SG 1 through SG 5, are almost the same and fall directly on the thermal-output curves from the strain gage manufacturer. A larger Telinde effect is exhibited in all five curves at temperatures below $-420^{\circ} \mathrm{F}$ compared to the Gr-Ep specimen. There should be minimal CTE mismatch between the substrate that has a CTE of $12.6 \times 10^{-6} /{ }^{\circ} \mathrm{F}$ and strain gages with a STC number of 13 in Table 1 . One curve, Al-2195 SG, will be used in subsequent discussions for the Al-2195 specimen for SGs 1, 2, 3, 4, and 5.

\section{E. Titanium data}

The apparent strain test results for the Titanium specimen are listed in Table 4, showing the averaged thermal output and the standard deviation for three runs. The averaged thermal output varies with temperature and the standard deviation of the thermal output is very low with respect to the averaged strain except at $-450^{\circ} \mathrm{F}$ for SGs 3 , 4 , and 5 .

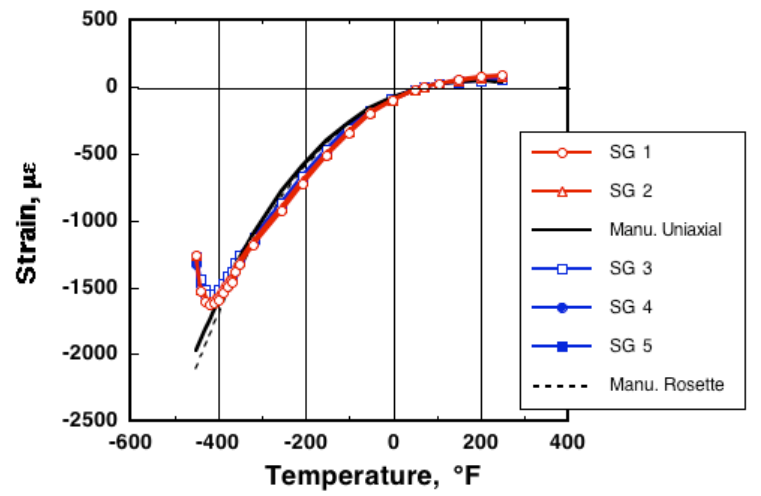

Figure 7. Apparent-strain results for the thermal output of the Al-2195 specimen strain gages over the temperature range of $-450^{\circ} \mathrm{F}$ to $+250^{\circ} \mathrm{F}$.

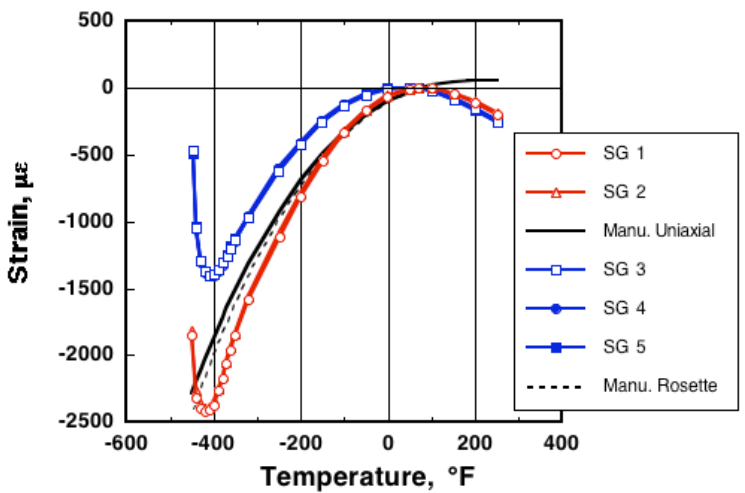

Figure 8. Apparent-strain results for the thermal output of the Titanium specimen strain gages over the temperature range of $-450^{\circ} \mathrm{F}$ to $+250^{\circ} \mathrm{F}$.

The data in Table 4 is plotted in Figure 8, where two dominant curves emerge. The first dominate curve is based on the two plotted curves of apparent-strain data for uniaxial gage, SG 1 and SG 2, in the $0^{\circ}$ - and $90^{\circ}$-directions, respectively. The second dominate curve is based on the three plotted curves of apparent-strain data for the rosette gage, SG 3, SG 4, and SG 5, in the $-45^{\circ}-, 0^{\circ}-$, and $+45^{\circ}$-directions, respectively. The thermal-output curves for the uniaxial and rosette gages from the strain gage manufacturer are also plotted in Figure 8. 
A very large Telinde effect is exhibited in all five curves at temperatures below $-410^{\circ} \mathrm{F}$ compared to the Gr-Ep and Al-2195 specimens. There should be minimal CTE mismatch between the substrate that has a CTE of 5.5x $10^{-6} /{ }^{\circ} \mathrm{F}$ and strain gages with a STC number of 06 in Table 1 . The large Telinde effect may be the cause for the high standard deviation at $-450^{\circ} \mathrm{F}$ for SGs 3,4 , and 5 .

Table 3. Averaged temperature-dependent apparent strain and standard deviation for the Al-2195 specimen with two uniaxial strain gages and a rosette strain gage.

\begin{tabular}{|c|c|c|c|c|c|c|c|c|c|c|}
\hline $\begin{array}{c}\text { Temp. } \\
{ }^{\circ} \mathrm{F}\end{array}$ & $\begin{array}{c}\text { SG } 1 \\
\mu \varepsilon\end{array}$ & $\begin{array}{c}\text { St. Dev. } \\
\text { SG } 1 \\
\mu \varepsilon\end{array}$ & $\begin{array}{c}\text { SG } 2 \\
\mu \varepsilon\end{array}$ & $\begin{array}{c}\text { St. Dev. } \\
\text { SG } 2 \\
\mu \varepsilon\end{array}$ & $\begin{array}{c}\text { SG } 3 \\
\mu \varepsilon\end{array}$ & $\begin{array}{c}\text { St. Dev. } \\
\text { SG } 3 \\
\mu \varepsilon\end{array}$ & $\begin{array}{c}\mathrm{SG} 4 \\
\mu \varepsilon\end{array}$ & $\begin{array}{c}\text { St. Dev. } \\
\text { SG } 4 \\
\mu \varepsilon \\
\end{array}$ & $\begin{array}{c}\text { SG } 5 \\
\mu \varepsilon\end{array}$ & $\begin{array}{c}\text { St. Dev. } \\
\text { SG } 5 \\
\mu \varepsilon\end{array}$ \\
\hline+250 & 88 & 6 & 79 & 7 & 52 & 5 & 66 & 5 & 53 & 4 \\
\hline+200 & 53 & 3 & 50 & 3 & 39 & 4 & 46 & 4 & 41 & 4 \\
\hline+150 & 73 & 3 & 66 & 2 & 47 & 4 & 58 & 4 & 48 & 4 \\
\hline+100 & 28 & 3 & 27 & 3 & 22 & 2 & 25 & 3 & 23 & 2 \\
\hline+70 & 0 & 1 & 0 & 0 & 0 & 0 & 0 & 0 & 0 & 1 \\
\hline+50 & -23 & 2 & -22 & 2 & -20 & 2 & -22 & 2 & -21 & 1 \\
\hline 0 & -101 & 1 & -97 & 1 & -90 & 1 & -96 & 1 & -92 & 1 \\
\hline-50 & -200 & 4 & -193 & 4 & -180 & 3 & -189 & 4 & -183 & 4 \\
\hline-100 & -341 & 17 & -331 & 17 & -310 & 16 & -322 & 16 & -315 & 16 \\
\hline-150 & -510 & 6 & -497 & 6 & -470 & 6 & -485 & 4 & -476 & 5 \\
\hline-200 & -719 & 35 & -702 & 34 & -670 & 33 & -688 & 32 & -676 & 33 \\
\hline-250 & -925 & 5 & -904 & 6 & -867 & 6 & -890 & 5 & -874 & 6 \\
\hline-320 & -1184 & 1 & -1159 & 1 & -1126 & 0 & -1163 & 1 & -1129 & 2 \\
\hline-350 & -1331 & 10 & -1301 & 4 & -1260 & 3 & -1302 & 1 & -1271 & 1 \\
\hline-360 & -1386 & 7 & -1348 & 2 & -1317 & 12 & -1357 & 10 & -1324 & 9 \\
\hline-370 & -1460 & 14 & -1419 & 15 & -1384 & 17 & -1425 & 15 & -1390 & 15 \\
\hline-380 & -1499 & 6 & -1453 & 5 & -1420 & 22 & -1460 & 23 & -1424 & 22 \\
\hline-390 & -1543 & 15 & -1498 & 12 & -1471 & 18 & -1511 & 21 & -1475 & 21 \\
\hline-400 & -1592 & 19 & -1550 & 17 & -1522 & 26 & -1562 & 30 & -1528 & 29 \\
\hline-410 & -1622 & 6 & -1585 & 6 & -1550 & 7 & -1592 & 10 & -1559 & 9 \\
\hline-420 & -1631 & 4 & -1604 & 4 & -1548 & 16 & -1594 & 12 & -1565 & 9 \\
\hline-430 & -1601 & 23 & -1584 & 7 & -1521 & 40 & -1570 & 34 & -1544 & 30 \\
\hline-440 & -1524 & 20 & -1514 & 29 & -1442 & 49 & -1493 & 44 & -1470 & 40 \\
\hline-450 & -1265 & 66 & -1260 & 70 & -1272 & 16 & -1326 & 13 & -1304 & 12 \\
\hline \multicolumn{11}{|c|}{$\begin{array}{l}\text { Note: } \\
\text { SG } 1 \text { is a uniaxial strain gage in the } 0^{\circ} \text {-direction. } \\
\text { SG } 2 \text { is a uniaxial strain gage in the } 90^{\circ} \text {-direction. } \\
\text { SG } 3 \text { is arm-1 of a rosette strain gage in the }-45^{\circ} \text {-direction. } \\
\text { SG } 4 \text { is arm-2 of a rosette strain gage in the } 0^{\circ} \text {-direction. } \\
\text { SG } 5 \text { is arm-3 of a rosette strain gage in the }+45^{\circ} \text {-direction. }\end{array}$} \\
\hline
\end{tabular}

The averaged thermal-output curves for the uniaxial and rosette strain gages should have been the same since the Titanium specimen is isotropic. The averaged thermal output for the uniaxial and rosette strain gages on the Al2195 specimen are almost the same. The thermal-output curves for the uniaxial and rosette strain gages from the strain gage manufacturer in Figure 8 diverge at temperatures below $-150^{\circ} \mathrm{F}$. The thermal-output curve for all of the strain gages should have fallen on the same curve as in Figure 7 for the Al-2195 specimen. Since the thermal-output curve for the uniaxial gage diverged upward from the thermal-output curve for the rosette, the thermal-output curves for the uniaxial gages SGs 1 and 2 rotate in a counter-clockwise-direction and became more linear. The thermaloutput curves SGs 3, 4, and 5 rotate in a clockwise-direction and became more non-linear since the thermal-output curve for the rosette gage diverged downward from the thermal-output curve for the uniaxial gage. Sensitivity of the 
STC 06 strain gage or the methods used to adhere the strain gage to the substrate may have also caused the difference in the thermal output for the Titanium specimen. Two curves, SG $1 \& 2$ for SGs 1 and 2, and SG 3\&4\&5, for SGs 3, 4, and 5, will be used in subsequent discussions for the Titanium specimen.

Table 4. Averaged temperature-dependent apparent strain and standard deviation for the Titanium specimen with two uniaxial strain gages and a rosette strain gage.

\begin{tabular}{c|c|c|c|c|c|c|c|c|c|c}
\hline \hline $\begin{array}{c}\text { Temp. } \\
{ }^{\circ} \mathrm{F}\end{array}$ & $\begin{array}{c}\text { SG 1 } \\
\mu \varepsilon\end{array}$ & $\begin{array}{c}\text { St. Dev. } \\
\text { SG 1 } \\
\mu \varepsilon\end{array}$ & $\begin{array}{c}\text { SG 2 } \\
\mu \varepsilon\end{array}$ & $\begin{array}{c}\text { St. Dev. } \\
\text { SG 2 } \\
\mu \varepsilon\end{array}$ & $\begin{array}{c}\text { SG 3 } \\
\mu \varepsilon\end{array}$ & $\begin{array}{c}\text { St. Dev. } \\
\text { SG 3 } \\
\mu \varepsilon\end{array}$ & $\begin{array}{c}\text { SG 4 } \\
\mu \varepsilon\end{array}$ & $\begin{array}{c}\text { St. Dev. } \\
\text { SG 4 } \\
\mu \varepsilon\end{array}$ & $\begin{array}{c}\text { SG 5 } \\
\mu \varepsilon\end{array}$ & $\begin{array}{c}\text { St. Dev. } \\
\mu \varepsilon\end{array}$ \\
\hline+250 & -202 & 9 & -188 & 7 & -253 & 7 & -247 & 7 & -259 & 8 \\
\hline+200 & -112 & 10 & -102 & 9 & -160 & 9 & -156 & 9 & -164 & 9 \\
\hline+150 & -48 & 8 & -42 & 7 & -84 & 8 & -83 & 8 & -87 & 7 \\
\hline+100 & -2 & 2 & -1 & 1 & -17 & 4 & -18 & 3 & -20 & 3 \\
\hline+70 & 0 & 0 & -1 & 0 & 1 & 0 & 0 & 0 & 0 & 1 \\
\hline+50 & -10 & 1 & -9 & 1 & 3 & 1 & 4 & 1 & 4 & 2 \\
\hline 0 & -63 & 2 & -61 & 2 & -7 & 3 & -4 & 3 & -5 & 3 \\
\hline-50 & -168 & 2 & -162 & 3 & -51 & 2 & -43 & 3 & -47 & 4 \\
\hline-100 & -331 & 3 & -320 & 4 & -135 & 1 & -123 & 2 & -132 & 1 \\
\hline-150 & -541 & 7 & -524 & 7 & -259 & 3 & -245 & 3 & -258 & 1 \\
\hline-200 & -810 & 9 & -786 & 9 & -427 & 4 & -410 & 3 & -426 & 6 \\
\hline-250 & -1112 & 3 & -1082 & 3 & -623 & 4 & -606 & 4 & -623 & 4 \\
\hline-320 & -1587 & 8 & -1560 & 1 & -971 & 7 & -964 & 2 & -965 & 6 \\
\hline-350 & -1852 & 41 & -1840 & 37 & -1141 & 9 & -1154 & 12 & -1131 & 13 \\
\hline-360 & -1965 & 25 & -1944 & 34 & -1199 & 11 & -1207 & 9 & -1186 & 10 \\
\hline-370 & -2066 & 42 & -2055 & 34 & -1255 & 15 & -1264 & 11 & -1246 & 6 \\
\hline-380 & -2176 & 42 & -2154 & 25 & -1310 & 22 & -1322 & 20 & -1310 & 11 \\
\hline-390 & -2267 & 62 & -2249 & 57 & -1363 & 21 & -1374 & 22 & -1363 & 20 \\
\hline-400 & -2370 & 42 & -2347 & 34 & -1395 & 19 & -1405 & 21 & -1391 & 21 \\
\hline-410 & -2406 & 30 & -2384 & 10 & -1400 & 23 & -1409 & 34 & -1396 & 45 \\
\hline-420 & -2416 & 43 & -2394 & 31 & -1369 & 29 & -1383 & 42 & -1373 & 48 \\
\hline-430 & -2400 & 43 & -2361 & 39 & -1294 & 45 & -1305 & 67 & -1290 & 73 \\
\hline-440 & -2314 & 19 & -2259 & 31 & -1043 & 15 & -1064 & 33 & -1036 & 34 \\
\hline-450 & -1855 & 73 & -1817 & 68 & -472 & 163 & -490 & 169 & -487 & 157 \\
\hline
\end{tabular}

Note:

SG 1 is a uniaxial strain gage in the $0^{\circ}$-direction.

SG 2 is a uniaxial strain gage in the $90^{\circ}$-direction.

SG 3 is arm- 1 of a rosette strain gage in the $-45^{\circ}$-direction.

SG 4 is arm- 2 of a rosette strain gage in the $0^{\circ}$-direction.

SG 5 is arm-3 of a rosette strain gage in the $+45^{\circ}$-direction.

\section{Extrapolation Approaches for Apparent-Strain Data}

An approach to extrapolate data must be developed if data at temperatures lower than $-320^{\circ} \mathrm{F}$ cannot be obtained and the specimen will experience temperatures lower than the apparent strain tests were able to achieve. Three extrapolation approaches are discussed in this section for the extrapolation of thermal-output data at temperature below $-320^{\circ} \mathrm{F}$.

The extrapolation is limited to $-430^{\circ} \mathrm{F}$ to since the Telinde effect ${ }^{4}$ occurs approximately at $-420^{\circ} \mathrm{F}$. If a subset of the $\mathrm{LN}_{2}$ results from $-320^{\circ} \mathrm{F}$ to $-100^{\circ} \mathrm{F}$ is used to generate a linear curve to extrapolate the $\mathrm{LN}_{2}$ results from $-320^{\circ} \mathrm{F}$ to $-430^{\circ} \mathrm{F}\left(<\mathrm{LH}_{2}\right.$ temperature, $\left.-423^{\circ} \mathrm{F}\right)$, one may be able to predict the thermal-output results at lower temperatures such as $-423^{\circ} \mathrm{F}$. Two approaches use a subset of the $\mathrm{LN}_{2}$ apparent-strain test data. Approach I uses the $\mathrm{LN}_{2}$ results 
from $-320^{\circ} \mathrm{F}$ to $-100^{\circ} \mathrm{F}$ and Approach II uses $\mathrm{LN}_{2}$ results from $-320^{\circ} \mathrm{F}$ to $-200^{\circ} \mathrm{F}$. The curvature of the $\mathrm{LN}_{2}$ results influences the extrapolation point at $-430^{\circ} \mathrm{F}$ more in Approach II than Approach I since less data is used for the extrapolation. A third approach is to extrapolate the $\mathrm{LN}_{2}$ curve-fit over the temperature range of $-320^{\circ} \mathrm{F}$ to $+250^{\circ} \mathrm{F}$ beyond $-320^{\circ} \mathrm{F}$ to $-430^{\circ} \mathrm{F}$.

Six thermal-output curves are evaluated in this section. The data from the apparent-strain tests data in Tables 2 , 3 , and 4 and Figures 6, 7, and 8, indicates that the thermal-output curves are characteristic for certain strain gages on particular substrates.

The slopes and $y$-intercepts for both approaches are calculated using a discrete least-squares polynomial fit ${ }^{16}$. The thermal-output values are determined at $-430^{\circ} \mathrm{F}$ using the calculated equations. Fourth-order polynomials are also calculated using a discrete least-square polynomial fit ${ }^{16}$ to a combined data set of the measured $\mathrm{LN}_{2}$ thermal output data $\left(-320^{\circ} \mathrm{F}\right.$ to $\left.+250^{\circ} \mathrm{F}\right)$ and the linearly extrapolated results at $-430^{\circ} \mathrm{F}$. Temperature-dependent functions for the thermal output, $\varepsilon_{T / 0}(T)^{9,11}$ for all three specimens are calculated using this method for Approaches I and II.

The curve-fit results for the two approaches are listed in Table 5 at a temperature of $-430^{\circ} \mathrm{F}$. The data is plotted over the full temperature range $\left(-430^{\circ} \mathrm{F}\right.$ to $\left.+250^{\circ} \mathrm{F}\right)$ in Figure 9 for the Gr-Ep specimen and in Figure 11 for the Al2195 and Titanium specimens. The data range is limited to the range of $-430^{\circ} \mathrm{F}$ to $-350^{\circ} \mathrm{F}$ in Figure 10 for the $\mathrm{Gr}-\mathrm{Ep}$ specimen and in Figure 12 for the Al-2195 and Titanium specimens.

Table 5. Results and differences for the extrapolated curve fit using the $\mathrm{LN}_{2}$ data using two approaches for a linear extrapolations (Approaches I and II), curve fit of the LHe data, and measured LHe data at a temperature of $-430^{\circ} \mathrm{F}$.

\begin{tabular}{l|c|c|c|c|c|c|c|c|c}
\hline \hline \multicolumn{1}{c|}{ Gage } & $\begin{array}{c}\text { Approach I } \\
\text { Curve Fit } \\
(1)\end{array}$ & $\begin{array}{c}\text { Approach II } \\
\text { Curve Fit } \\
(2)\end{array}$ & $\begin{array}{c}\text { LHe } \\
\text { Curve Fit } \\
(3)\end{array}$ & $\begin{array}{c}\text { Meas. } \\
\text { LHe } \\
(4) \\
\mu \varepsilon\end{array}$ & $\begin{array}{c}\text { A } \\
\text { Diff. } \\
(3-1) \\
\mu \varepsilon\end{array}$ & $\begin{array}{c}\text { B Diff. } \\
(3-2) \\
\mu \varepsilon\end{array}$ & $\begin{array}{c}\text { C } \\
\text { Diff. } \\
(4-1) \\
\mu \varepsilon\end{array}$ & $\begin{array}{c}\text { D } \\
\text { Diff. } \\
(4-2) \\
\mu \varepsilon\end{array}$ & $\begin{array}{c}\text { E } \\
\text { Diff. } \\
(4-3) \\
\mu \varepsilon\end{array}$ \\
\hline $\begin{array}{l}\text { Gr-Ep } \\
\text { SG 1\&4 }\end{array}$ & -5675 & -5759 & -5608 & -5515 & 67 & 151 & 160 & 243 & 93 \\
\hline $\begin{array}{l}\text { Gr-Ep } \\
\text { SG 2 }\end{array}$ & -962 & -1173 & -1567 & -1536 & -605 & -394 & -574 & -363 & 31 \\
\hline $\begin{array}{l}\text { Gr-Ep } \\
\text { SG 3\&5 }\end{array}$ & -3157 & -3313 & -3357 & -3224 & -200 & -44 & -67 & 89 & 133 \\
\hline $\begin{array}{l}\text { Al-2195 } \\
\text { SG }\end{array}$ & -1567 & -1610 & -1621 & -1564 & -55 & -11 & 2 & 46 & 57 \\
\hline $\begin{array}{l}\text { Titanium } \\
\text { SG 1\&2 }\end{array}$ & -2167 & -2295 & -2500 & -2381 & -333 & -205 & -214 & -86 & 119 \\
\hline $\begin{array}{l}\text { Titanium } \\
\text { SG 3\&4\&5 }\end{array}$ & -1353 & -1475 & -1416 & -1296 & -62 & 59 & 57 & 179 & 119 \\
\hline \hline
\end{tabular}

Note:

Approach I is calculated using apparent strain data extrapolated from $-320^{\circ} \mathrm{F}$ to $-100^{\circ} \mathrm{F}$.

Approach II is calculated using apparent strain data extrapolated from $-320^{\circ} \mathrm{F}$ to $-200^{\circ} \mathrm{F}$.

\section{A. Approach I}

The difference in results between Approach I and the measured thermal-output data for the strain gages on the Gr-Ep specimen are shown in column C, Table 5. The differences indicate that using Approach I was an adequate method to extrapolate data for strain gages Gr-Ep SG 1\&4 (difference of $160 \mu \varepsilon$ ) and Gr-Ep SG 3\&5 (difference of $-67 \mu \varepsilon)$. Strain gages Gr-Ep SG $1 \& 4$ and Gr-Ep SG $3 \& 5$ have fairly linear thermal-output curves in Figure 6. Approach I was not an adequate method for strain gage Gr-Ep SG 2 and had difference of $-574 \mu \varepsilon$ as shown in column C, Table 5. The thermal-output curve for strain gage Gr-Ep SG 2 was less linear than the thermal-output curves strain gage Gr-Ep SG 1\&4 in Figure 6. The separation between Approach I and the measured data is minimal in Figures 9 and 10 for strain gage Gr-Ep SG 1\&4. A slight separation between Approach I and the measured data is seen in Figures 9 and 10 for strain gage Gr-Ep SG 3\&5. A larger separation between Approach I and the measured data is seen for strain gage Gr-Ep SG 2 in Figure 9. The separation between Approach I and the measured data for strain gage Gr-Ep SG 2 can be readily seen in Figure 10 where Approach I under-estimates the thermal output when compared to the measured data. 
The results using Approach I for strain gage Al-2195 SG had good agreement with the LHe curve fit (difference of $-55 \mu \varepsilon$ ) and the measured data (difference of $-2 \mu \varepsilon$ ) as shown in the calculated differences in columns A and C, Table 5 and in Figures 11 and 12. The data plotted for strain gage Al-2195 SG in Figure 7 was also linear in the cryogenic temperature range below $-200^{\circ} \mathrm{F}$. The Titanium specimen results using Approach I for strain gage Titanium SG $1 \& 2$ did not have good agreement with the LHe curve fit $(-333 \mu \varepsilon)$ nor the measured data (difference of $-215 \mu \varepsilon$ ) as shown in the calculated differences in columns A and C, Table 5. There is a large difference between Approach I and the measured data for strain gage Titanium SG 1\&2 shown in Figure 12. The results for strain gage Titanium SG 3\&4\&5 using Approach I had good agreement with the LHe curve fit (difference of $-62 \mu \varepsilon$ ) and measured data (difference of $57 \mu \varepsilon$ ) as shown in the calculated differences in columns A and C, Table 5 and in Figures 11 and 12. Strain gage Titanium SG 3\&4\&5 was also more linear than strain gage Titanium SG $1 \& 2$ in Figure 8 .

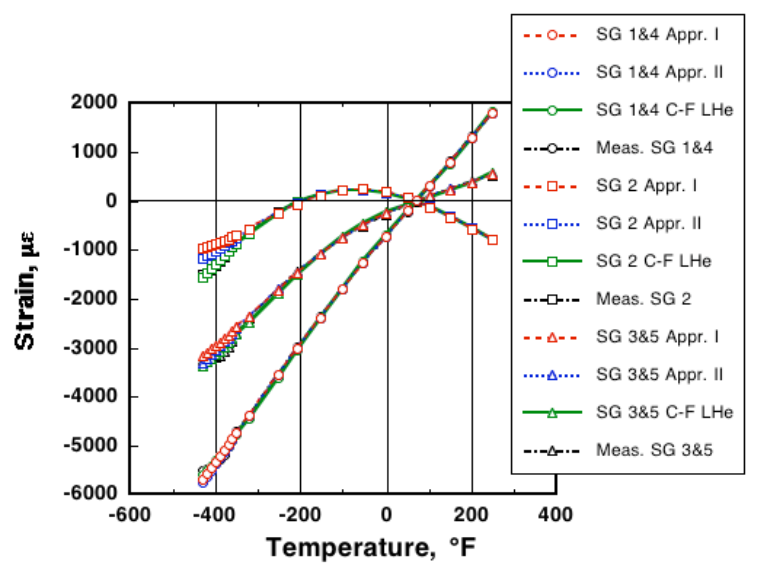

Figure 9. Approach I, Approach II, LHe curve-fit (C-F LHe), and measured thermaloutput results for the Gr-Ep specimen for SG $1 \& 4$, SG 2, and SG 3\&5 over the temperature range of $-450^{\circ} \mathrm{F}$ to $+250^{\circ} \mathrm{F}$.

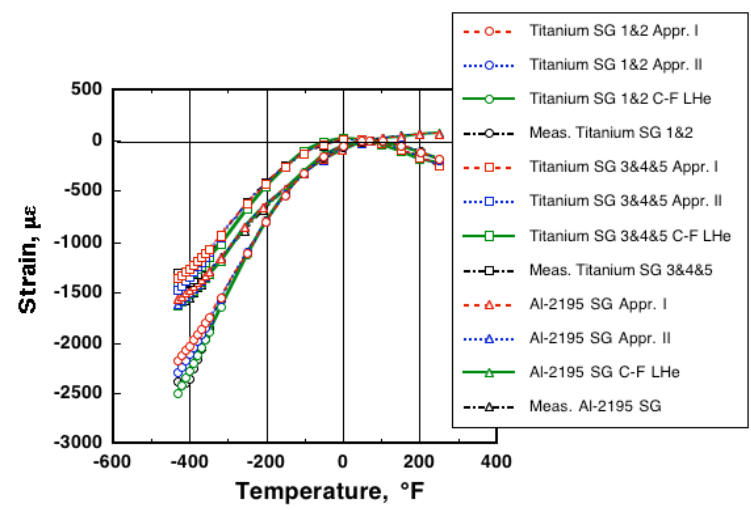

Figure 11. Approach I, Approach II, LHe curve-fit (C-F LHe), and measured thermal-output results for the Al-2195 specimen for Al-2195 SG and Titanium specimen for Titanium SG $1 \& 2$ and Titanium SG $3 \& 4 \& 5$ over the temperature range of $-450^{\circ} \mathrm{F}$ to $+250^{\circ} \mathrm{F}$.

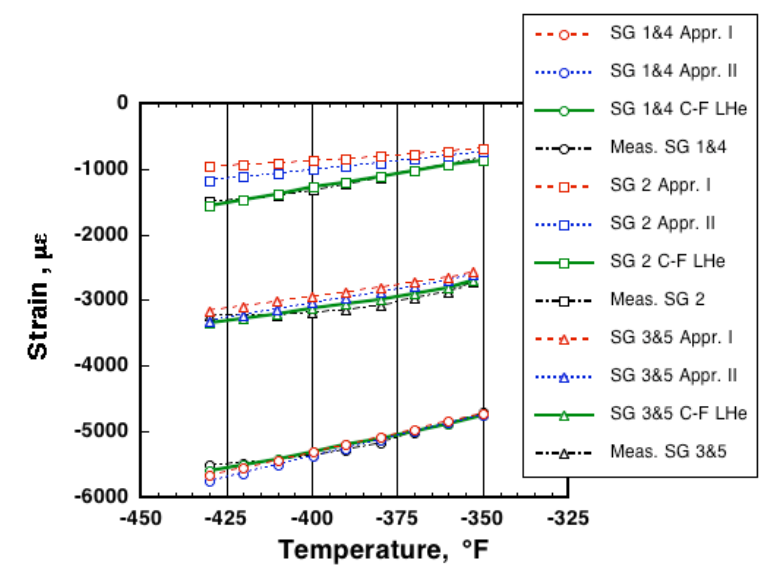

Figure 10. Approach I, Approach II, LHe curvefit (C-F LHe), and measured thermal-output results for the Gr-Ep specimen for SG 1\&4, SG 2, and SG $3 \& 5$ over the temperature range of $-450^{\circ} \mathrm{F}$ to $350^{\circ} \mathrm{F}$.

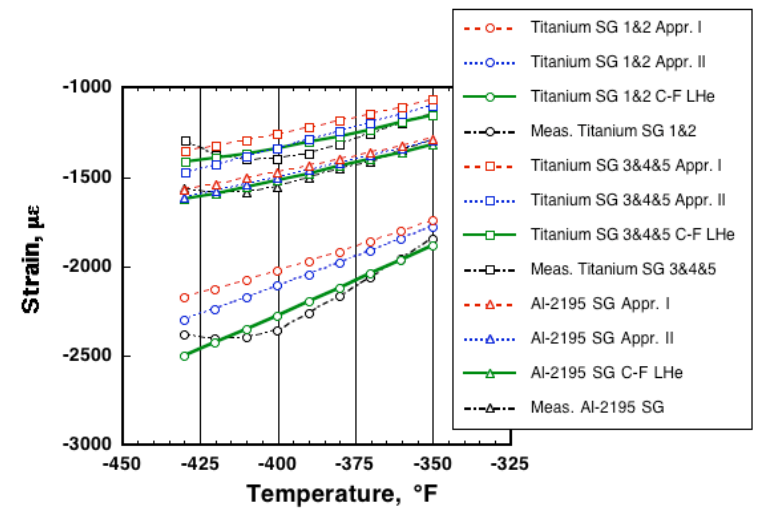

Figure 12. Approach I, Approach II, LHe curve-fit (C-F LHe), and measured thermal-output results for the Al-2195 specimen for SG and Titanium specimen for Titanium SG 1\&2 and Titanium SG $3 \& 4 \& 5$ over the temperature range of $-450^{\circ} \mathrm{F}$ to $-350^{\circ} \mathrm{F}$.

\section{B. Approach II}

All of the strain gages on all of the specimens had good agreement with the measured data described in Figures 9 and 11 , when the temperature was above $-320^{\circ} \mathrm{F}$ using Approach II. Approach II had good agreement with the measured data in column D, Table 5 for the strain gages Gr-Ep SG 3\&5 (difference of $72 \mu \varepsilon$ ), Al-2195 SG 
(difference of $46 \mu \varepsilon$ ), and Titanium SG 1\&2 (difference of -86 $\mu \varepsilon$ ) versus Approach I (column C, Table 5). Approach II in column D, Table 5 provides a better approximation to the measured data for the Gr-Ep SG 2 (difference of $-319 \mu \varepsilon$ ) than Approach I (difference of $-529 \mu \varepsilon$ in column C, Table 5) when comparing to the measured data. The strain gages Gr-Ep SG 3\&5 and Al-2195 SG had good agreement using Approach II with the measured data shown in Figures 10 and 12, while strain gages Gr-Ep SG 2 and Titanium SG 1\&2 had a slight separation from the measured data when using Approach II. Approach II (column D, Table 5) did not have as good agreement with the measured data for strain gages Gr-Ep SG $1 \& 4$ (difference of $249 \mu \varepsilon$ ) and Titanium SG $3 \& 4 \& 5$ (difference of $179 \mu \varepsilon$ ) as Approach I (column C, Table 5) at $-430^{\circ}$ F. Strain gages Gr-Ep SG $1 \& 4$ and Titanium SG $3 \& 4 \& 5$ had better agreement with the measured data using Approach II than strain gage Gr-Ep SG 2 using Approach II (column D, Table 5) and in Figures 10 and 12. This result occurred because the thermal-output curves for strain gages Gr-Ep SG $1 \& 4$ and Titanium SG $3 \& 4 \& 5$ in Figures 6 and 7, respectively are much more linear in shape than the thermal-output curve for strain gage Gr-Ep SG 2 in Figure 6. The thermal-output curve for the GrEp SG 2 is highly non-linear compared to Gr-Ep SG $1 \& 4$ in Figure 6 and more of a slope is required to accurately extrapolate the thermal-output curve to $-430^{\circ} \mathrm{F}$.

Approach II provided good agreement for all of the strain gages above the temperature of $-420^{\circ} \mathrm{F}$, but was best for strain gage curves that have a non-linear shape at temperatures below $-320^{\circ} \mathrm{F}$, except for strain gage Gr-Ep SG 2 . Approach II took into account the non-linear shape of the $\mathrm{LN}_{2}$ curve by using less data defining the $\mathrm{LN}_{2}$ curve than Approach I. By using less data, the slope of the linear extrapolation was steeper downward, better following the shape of the non-linear thermal-output curves than Approach I.

\section{Approach III}

A third approach to extrapolate the data to obtain thermal-output values at lower temperatures is to create a curve fit for the existing data to $\mathrm{LN}_{2}$ temperatures and then generate thermal-output data at the temperatures outside of the range of known data with the created curve fit. Using this approach is problematic since the data may have significant errors just outside of the bounds of the original data. However, if one knows the characteristic shape of the thermal-output curves and if one does not use values too far outside of the known bounds of data, reasonable solutions can be obtained.

The results using Approach III at a temperature of $-430^{\circ} \mathrm{F}$ are listed in Table 6. The results at all temperatures are plotted in Figures 13 and 14 for strain gages Gr-Ep SG 1\&4, Gr-Ep SG 2, and Gr-Ep SG 3\&5 and in Figures 15 and 16 for strain gages Al-2195 SG, Titanium SG $1 \& 2$, and Titanium SG $3 \& 4 \& 5$. The data is plotted over the full temperature range $\left(-430^{\circ} \mathrm{F}\right.$ to $\left.+250^{\circ} \mathrm{F}\right)$ in Figures 13 and 15 , and in Figures 14 and 16 the data range is only $-430^{\circ}$ to $-350^{\circ} \mathrm{F}$. The difference between Approach III and the measured data (column B, Table 6) is greater for the strain gages that have almost linear thermal-output curves at the lower temperatures (strain gages Gr-Ep SG 1\&4 [difference of $433 \mu \varepsilon$ ] and Titanium SG $3 \& 4 \& 5$ [difference of $363 \mu \varepsilon$ ]) except for strain gage Al-2195 SG (difference of $-16 \mathrm{me}$ ). The results using Approach III for strain gages that have less-linear thermal-output curves (strain gages Gr-Ep SG 2 [difference of $-48 \mu \varepsilon$ ] and Titanium SG 1\&2 [difference of $6 \mu \varepsilon$ ]) have very good agreement with the measured data (column B, Table 6) than the strain gages with near-linear thermal-output curves except for strain gage Gr-Ep SG $3 \& 5$ (difference of $334 \mu \varepsilon$ ).

A large separation between the $\mathrm{LN}_{2}$ curve and measured data can be seen in Figure 14 for strain gages Gr-Ep SG $1 \& 4$ and Gr-Ep SG 3\&5. Strain gage Gr-Ep SG 2 has minimal separation between Approach III and the measured data in Figure 14. There is not a large separation between Approach III and the measured data for the strain gages Al-2195 SG and Titanium SG 1\&2 in Figure 16. Strain gage Titanium SG 3\&4\&5 has a large difference between Approach III and the measured data at $-430^{\circ} \mathrm{F}$ (column B, Table 6) and in Figure 16. Strain gage Al-2195 SG could have used both Approaches I and II to extrapolate data to $-430^{\circ} \mathrm{F}$. The thermal-output curve for Al-2195 SG is an intermediate linear curve below the $\mathrm{LN}_{2}$ temperatures region. The thermal-output curve for strain gage Al-2195 SG, however, is strongly influenced by other portions of the curve $\left(-200^{\circ} \mathrm{F}\right.$ to $\left.0^{\circ} \mathrm{F}\right)$.

\section{Summary}

Apparent-strain tests were conducted on Gr-Ep, Al-2195, and Titanium specimens to determine the temperaturedependent thermal output or apparent strain of strain gages bonded on the specimens. Curve fits of the thermaloutput data were developed for real-time strain correction of thermal mismatch between the strain gage and the substrate of the specimen during combined thermal and mechanical tests. Three approaches to extrapolate the thermal-output data to temperatures below the apparent-strain test temperatures were presented. 
Table 6. Results and differences for extrapolating a curve fit using Approach III, curve fit of the LHe data, and measured $\mathrm{LHe}$ data at a temperature of $-430^{\circ} \mathrm{F}$.

\begin{tabular}{l|c|c|c|c|c|c}
\hline \hline \multicolumn{1}{c|}{ Gage } & $\begin{array}{c}\text { Approach III } \\
\text { Curve Fit } \\
(1)\end{array}$ & $\begin{array}{c}\text { LHe } \\
\text { Curve Fit } \\
(2) \\
\mu \varepsilon\end{array}$ & $\begin{array}{c}\text { Meas. } \\
\text { LHe } \\
(3) \\
\mu \varepsilon\end{array}$ & $\begin{array}{c}\text { A } \\
\text { Diff. } \\
(2-1) \\
\mu \varepsilon\end{array}$ & $\begin{array}{c}\text { B } \\
\text { Diff. } \\
(3-1) \\
\mu \varepsilon\end{array}$ & $\begin{array}{c}\text { C } \\
\text { Diff. } \\
(3-2) \\
\mu \varepsilon\end{array}$ \\
\hline $\begin{array}{l}\text { Gr-Ep } \\
\text { SG 1\&4 }\end{array}$ & -5943 & -5608 & -5510 & 335 & 433 & 98 \\
\hline $\begin{array}{l}\text { Gr-Ep } \\
\text { SG 2 }\end{array}$ & -1444 & -1567 & -1492 & -123 & -48 & 75 \\
\hline $\begin{array}{l}\text { Gr-Ep } \\
\text { SG 3\&5 }\end{array}$ & -3576 & -3357 & -3242 & 218 & 334 & 115 \\
\hline $\begin{array}{l}\text { Al-2195 } \\
\text { SG }\end{array}$ & -1548 & -1621 & -1564 & -73 & -16 & 57 \\
\hline $\begin{array}{l}\text { Titanium } \\
\text { SG 1\&2 }\end{array}$ & -2387 & -2500 & -2381 & -113 & 6 & 119 \\
\hline $\begin{array}{l}\text { Titanium } \\
\text { SG 3\&4\&5 }\end{array}$ & -1659 & -1416 & -1296 & 243 & 363 & 119 \\
\hline \hline
\end{tabular}

The extrapolation of thermal-output data over the temperature range from $-320^{\circ} \mathrm{F}$ to $+250^{\circ} \mathrm{F}$ to temperatures lower than $-320^{\circ} \mathrm{F}$ with a linear extension to $-430^{\circ} \mathrm{F}$ based on data over the temperature range of $-320^{\circ} \mathrm{F}$ to $+100^{\circ} \mathrm{F}$ was Approach I. Approach I had good agreement with measured thermal-output data at the lower temperatures except for strain gages that had non-linear thermal-output curves at the lower temperatures.

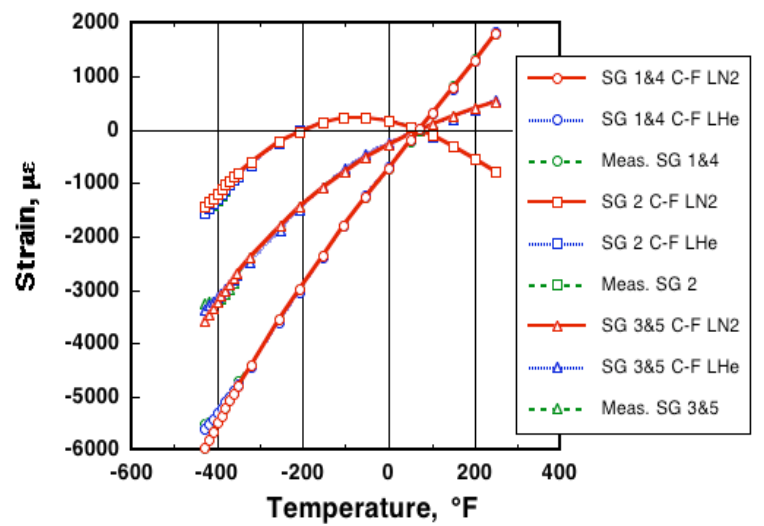

Figure 13. $\quad \mathrm{LN}_{2}$ curve-fit $\left(\mathrm{C}-\mathrm{F} \mathrm{LN}_{2}\right)$, LHe curvefit (C-F LHe), and measured thermal-output results for the Gr-Ep specimen for SG 1\&4, SG 2, and $S G 3 \& 5$ over the temperature range of $-450^{\circ} \mathrm{F}$ to $+250^{\circ} \mathrm{F}$.

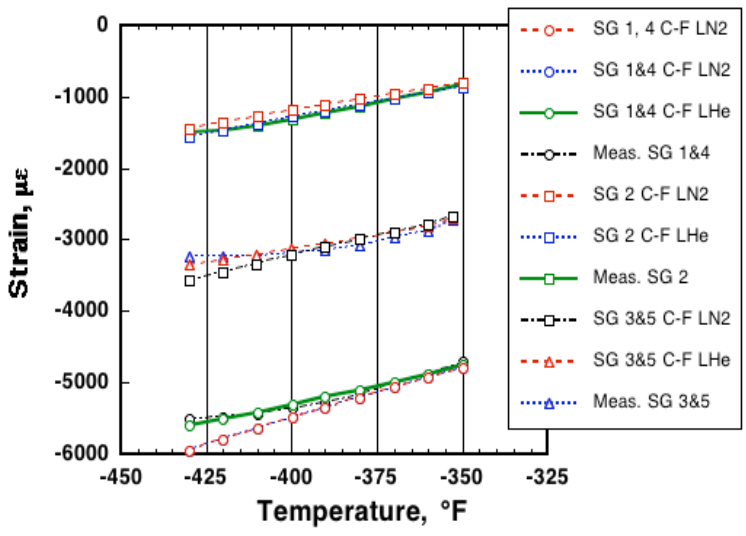

Figure 14. $\mathrm{LN}_{2}$ curve-fit $\left(\mathrm{C}-\mathrm{F} \mathrm{LN}_{2}\right)$, LHe curvefit (C-F LHe), and measured thermal-output results for the Gr-Ep specimen for SG 1\&4, SG 2, and SG $3 \& 5$ over the temperature range of $-450^{\circ} \mathrm{F}$ to $-\mathbf{3 5 0}^{\circ} \mathrm{F}$.

Approach II also used extrapolation of thermal-output data over the temperature range from $-320^{\circ} \mathrm{F}$ to $+250^{\circ} \mathrm{F}$ with a linear extension to $-430^{\circ} \mathrm{F}$ but the linear extension was based on data over the temperature range of $-320^{\circ} \mathrm{F}$ to $-200^{\circ} \mathrm{F}$. Approach II had better agreement with measured thermal-output data at the lower temperatures than Approach I for strain gages that had non-linear thermal-output curves at temperatures less than $-320^{\circ} \mathrm{F}$.

The extrapolation of data over the temperature range from $-320^{\circ} \mathrm{F}$ to $+250^{\circ} \mathrm{F}$ without a linear extension was used in Approach III. The results obtained from Approach III were similar to the measured data for strain gages that had highly non-linear thermal-output curves at temperatures below $-320^{\circ} \mathrm{F}$. However, using Approach III for strain gages that had linear thermal-output curves at temperatures less than $-320^{\circ} \mathrm{F}$, produced a significant difference when compared to the measured thermal output data. Approach III should not be used in place of Approaches I and II. 
An apparent-strain test to the lowest test temperature possible should be performed with the actual test article or coupons. If the desired lowest test temperature cannot be achieved, a non-mechanical load induced state cannot be achieved, or one is not willing to use witness or "dummy" strain gages to compensate for temperature change, then Approach I or Approach II should be used to develop thermal-output data beyond the apparent-strain test rage. Approach I or Approach II can be used to aid in real-time strain correction in combined thermal and mechanical tests, if the characteristic shape of the thermal output is known and apparent-strain data is limited.

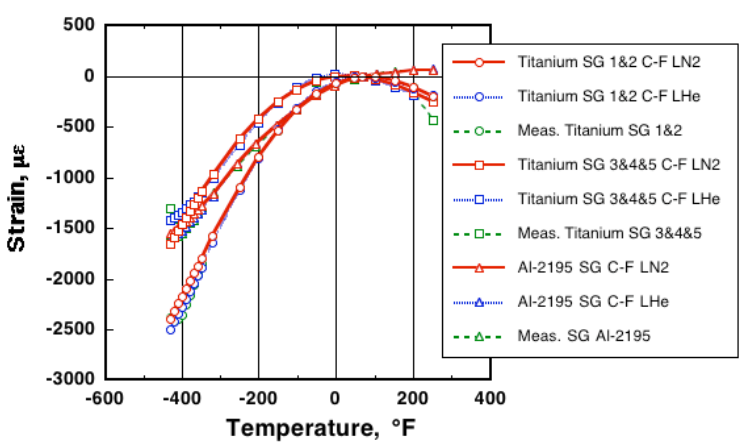

Figure 15. $\quad \mathrm{LN}_{2}$ curve-fit $\left(\mathrm{C}-\mathrm{F} \mathrm{LN}_{2}\right)$, LHe curvefit (C-F LHe), and measured thermal-output results for the Al-2195 specimen for Al-2195 SG and Titanium specimen for Titanium SG $1 \& 2$ and Titanium SG $3 \& 4 \& 5$ over the temperature range of $-450^{\circ} \mathrm{F}$ to $+250^{\circ} \mathrm{F}$.

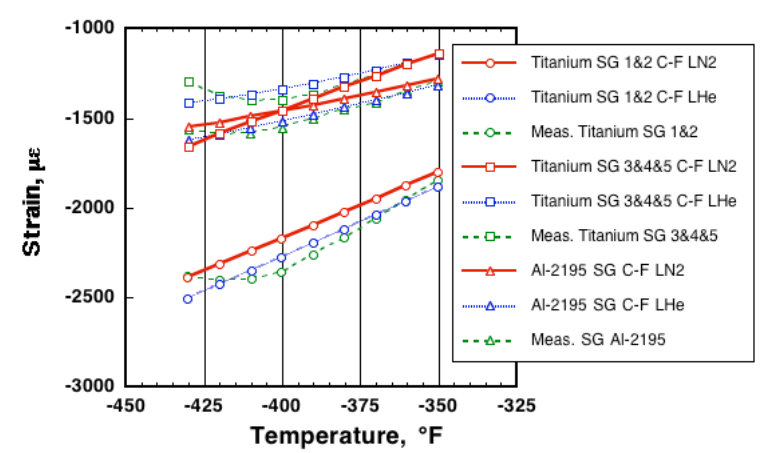

Figure 16. $\quad \mathrm{LN}_{2}$ curve-fit (C-F $\left.\mathrm{LN}_{2}\right)$, LHe curvefit (C-F LHe), and measured thermal-output results for the Al-2195 specimen for Al-2195 SG and Titanium specimen for Titanium SG $1 \& 2$ and Titanium SG $3 \& 4 \& 5$ over the temperature range of $-450^{\circ} \mathrm{F}$ to $-350^{\circ} \mathrm{F}$.

\section{Acknowledgments}

The authors thank Tom Moore, Mark Roth, Mark Clemons, and David Hare of LaRC for bonding on the strain gages and thermocouple and ensuring that we received the highest quality of workmanship. We also thank David Glass of LaRC Third Generation Reusable Launch Vehicle Program Office for funding the purchase of LHe for the cryogenic testing.

\section{References}

${ }^{1}$ Freeman, Jr., D. C., Stanley, D. O., Camarda, C. J., Lepsch, R. A., Cook, S. A., "Single-Stage-To-Orbit-A Step Closer," Proceeding of the $45^{\text {th }}$ Congress of the International Astronautical Federation (IAF), October 1994, IAF 94-V3.534.

${ }^{2}$ Johnson, T. F., Natividad, R., Rivers, H. K., Smith, R., “Thermal Structures Technology Development for Reusable Launch Vehicle Cryogenic Propellant Tanks,” NASA TM-2005-213913, Aug. 2005.

${ }^{3}$ Mikesell, R. S., Clark, D. R., Speck M. L., "A Compensation Technique for Strain Measurements in Cryogenic Environments," Experimental Techniques, Vol. 14, pp. 26-32, Sept.-Oct., 1990.

${ }^{4}$ Telinde, J. C., "Strain Gages in Cryogenic Environments," Journal of Experimental Mechanics, Vol. 10, No. 9, pp. 10.

${ }^{5}$ Ferris, A. T., "Force Instrumentation for Cryogenic Wind Tunnel Using One-Piece Strain-Gage Balances," NASA TM-81845, June 1980.

${ }^{6}$ Ferris, A. T., "Cryogenic Strain Gage Techniques Used in Force Balance Design for the National Transonic Facility," NASA TM-87712, May 1986.

${ }^{7}$ Johnson, T. F, Weiser, E. S., Duong, P. G., "Cryogenic Insulation Bondline Studies for Reusable Launch Vehicles," Joint Army-Navy-NASA-Air Force (JANNAF) 2003 Conference, Colorado Springs, CO, Dec. 2003.

${ }^{8}$ Rivers, H. K., "Cyclic Cryogenic Thermal-Mechanical Testing of an X-33/RLV Liquid Oxygen Tank Concept," NASA TM-1999-209560, Sept. 1999.

${ }^{9}$ Kowalkowski, M. K., Rivers, H. K., Smith, R. W., "Thermal Output of WK-Type Strain Gauges on Various Materials at Cryogenic and Elevated Temperatures,"NASA/TM-1998-208739, Oct. 1998.

${ }^{10}$ Moore, T. C., "Recommended Strain Gage Application Procedures for Various Langley Research Center Balances and Test Articles," NASA TM-110327, March 1997. 
${ }^{11}$ Anonymous, "Strain Gage Thermal Output and Gage Factor Variation with Temperature," Micromeasurements Group-TN-504-1, 2004.

${ }^{12}$ Johnson, T. F., Gates, T. S., "High Temperature Polyimide Materials In Extreme Temperature Environments," AIAA-2001-1214, AIAA 42nd Annual AIAA/ASME/ASCE/AHS/ASC Structures, Structural Dynamics, and Materials Conference, Seattle, WA, April 2001.

${ }^{13}$ Anonymous, "Design Values for Aluminum Alloy 2195," Drawing No. 809-3510, Lockheed Martin, New Orleans, LA, March 1997.

${ }^{14}$ Boyer, R. Welsch, G., Collings, E. W., "Material Properties Handbook: Titanium Alloys," ASM International, Materials Park, OH, 1994.

${ }^{15}$ Tsai, S. W., Composites Design, Third Edition, Think Composites, Dayton, OH, 1987.

${ }^{16}$ Burden, R. L., Faires, J. D., Numerical Analysis, Third Edition, Prindle, Weber, and Schmidt, Boston, MA, 1995. 